\title{
DDidático: Sistema web para elaboração de desenhos didáticos de cursos à distância
}

\author{
Ísis N. C. Costa Paiva ${ }^{1}$, Suellem S. Fernandes Queiroz ${ }^{1}$, Alysson Mendes de Oliveira ${ }^{1}$, \\ Regina Santos Young ${ }^{1}$ \\ ${ }^{1}$ Departamento de Informática - Universidade do Estado do Rio Grande do Norte (UERN) \\ Caixa Postal 59.610-210 - Mossoró - RN - Brasil \\ \{isis.nataly.2, suellem.sfq\}@gmail.com, \{alyssonoliveira, reginayoung\}@uern.br
}

\begin{abstract}
Distance Education and Technology is currently being set up, both by the medium and the Virtual Learning Environments (AVA's). Teaching didactics, drawing, pedagogy, drawing Didactic Design (DD). However, DD filling is often done by means of e-mail exchange, which makes it difficult to systematically view the process and becomes ineffective. In this way, a web system was developed that aims to assist in the process of creation and evaluation of DDs, with the application in the real environment of the Directorate of Distance Education (DEaD) of UERN (University of Rio Grande do Norte State).
\end{abstract}

Resumo. A Educação à Distância e a Tecnologia estão estreitamente ligados atualmente, tanto por meio dos Ambientes Virtuais de Aprendizagem (AVA's), quanto no auxílio em funções administrativas. Cada instituição de Educação a Distância possui seu próprio modelo pedagócio, chamado Desenho Didático (DD). Entretanto, o preenchimento do DD é feito muitas vezes por meio de troca de e-mails, o que dificulta a visualização sistemática do processo e a torna ineficiente. Dessa forma, foi desenvolvida uma sistema web que tem o objetivo de auxiliar no processo de criação e avaliação de DD's, com aplicação em ambiente real da Diretoria de Educação a Distância (DEaD) da UERN (Universidade do Estado do Rio Grande do Norte).

\section{Introdução}

A adoção dos Ambientes Virtuais de Aprendizagem (AVAs) na EaD (Educação a Distância) vem fazendo com que esta e a Tecnologia estejam intimamente ligados, tanto para a realização das aulas, quanto no processo de planejamento.

Cada instituição de EaD possui seu próprio modelo pedagógico. O documento Desenho Didático (DD), fazendo parte deste modelo, contém todos os dados referentes à configuração da disciplina em um AVA, Ambiente Virtual de Aprendizagem. Na DEaD (Diretoria de Educação a Distância da Universidade Estadual do Rio Grande do Norte), o preenchimento deste documento acontece entre troca de emails e arquivos de texto entre os professores ministrantes de disciplinas, a coordenação pedagógica e a equipe de suporte. Esse fluxo de trabalho não se mostrava muito eficiente, pois, dificultava a visualização sistemática do processo.

Dessa forma, foi pensado em utilizar um software como facilitador de processo para auxiliar. E uma aplicação web, um sistema de computador que realiza as funções que lhe foram especificadas utilizando um navegador web (browser) como cliente, foi escolhida para este trabalho. 


\subsection{Objetivos}

O objetivo geral deste trabalho é desenvolver uma aplicação web para auxiliar no processo de criação e avaliação de DD's para a Diretoria de Educação a Distância da UERN.

Este trabalho tem como objetivos específicos:

- Entender um pouco sobre a EaD no Brasil;

- Criar noções sobre Design Instrucional e DD;

- Estudar o funcionamento de Aplicações web;

- Desenvolver Aplicação Web utilizando o Framework de desenvolvimento WEB Django, que utiliza a linguagem python

\section{Educação EaD}

Atualmente, a Educação EaD e a Tecnologia estão intimamente ligados, tanto por meio dos AVA's, quanto por meio de auxílio em funções administrativas. A EaD já existe há bastante tempo, os cursos por correspondência utilizando os correios por exemplo, mas não havia muitos meios além deste. Com o avanço da tecnologia, em especial da internet, foi possível que outras formas de ensino a distância se desenvolvessem.

Assim, o Governo Federal regulamentou pelo Decreto $\mathrm{n}^{\circ} 5622$ de 19 de dezembro de 2005, a modalidade de Educação a Distância em todo território nacional. Conforme esse decreto: caracteriza-se a educação a distância como modalidade educacional na qual a mediação didático-pedagógica nos processos de ensino e aprendizagem ocorre com a utilização de meios e tecnologias de informação e comunicação, com estudantes e professores desenvolvendo atividades educativas em lugares ou tempos diversos [Brasil 2014].

Os elementos destacados nos Referenciais quanto à criação de um curso na modalidade a distância, são: “(i) concepção de educação e currículo; (ii) sistemas de comunicação; (iii) material didático; (iv) avaliação; (v) equipe multidisciplinar; (vi) infraestrutura de apoio; (vii) gestão acadêmico-administrativa; (viii) sustentabilidade financeira" [Brasil 2007].

Um modelo pedagógico para $\mathrm{EaD}$ é um sistema de premissas teóricas que explicam a forma de abordar o currículo e que se concretiza nas práticas pedagógicas e nas interações professor/aluno/objeto de estudo. Cada instituição possui seu próprio modelo pedagógico e é de sua responsabilidade modelá-lo de forma que exista um bom funcionamento, sempre pensando no melhor uso das ferramentas e de tecnologias para seus cursos [Santiago 2014].

No Brasil solidifica-se como predominante a EaD baseada na interação proporcionada pelas tecnologias interativas, principalmente a internet, fazendo uso dos AVA como principais ferramentas. AVAs são instrumentos mediadores entre professor e estudante, que funcionam como uma sala de aula virtual no qual os alunos têm acesso às aulas e materiais didáticos preparados para cada curso. Para que se possa alimentar o AVA com as informações necessárias, é preciso que tudo esteja planejado e detalhado, sem informações ambíguas, com antecedência [Neves et al. 2012].

\subsection{Design Educacional e o DD}

No cenário da oferta de uma disciplina, assim como na produção dos conteúdos, o planejamento é um instrumento de importância significativa, pois é através dele que serão detalhadas todas as ações para execução das atividades de ensino e aprendizagem. Ele também 
orientará a equipe técnica na configuração da disciplina no AVA. Esse planejamento será conduzido conforme o modelo pedagógico adotado pela instituição que servirá de norte para o desenvolvimento das atividades das equipes [Santiago 2014].

O design instrucional, ou educacional, termo que os autores [Neves et al. 2012] preferem, é a concepção e o desenvolvimento de projetos para $\mathrm{EaD}$, que tem como produtos finais, além do projeto pedagógico em si, os materiais didáticos. Essa metodologia se apropriou de práticas, teorias e atividades da educação convencional e, ao adequá-las à modalidade não presencial, conseguiu resultados que podem ser expressos em números cada vez mais crescentes de adesão em todo o mundo.

O planejamento da fase de oferta é decorrente do trabalho colaborativo entre professores-formadores e designer educacionais [Santiago 2014], que desenvolvem um documento de planejamento chamado DD, contendo todos os dados referentes à configuração da disciplina, descrição das atividades, metodologia adotada, formato de avaliação, atores envolvidos e datas de execução.

Um DD, segundo [Santos and Silva 2009] é a arquitetura de conteúdos e de situações de aprendizagem para estruturar uma sala da aula online, contemplando as interfaces de conteúdo e de comunicação. Assim, o DD serve como um modelo, ou guia, para que o professor possa definir sua disciplina seguindo os passos necessários para detalhar todos os pontos de suas aulas e recursos do AVA que utilizará.

\section{Tecnologias e ferramentas utilizadas no DDidático}

Nessa seção serão incluídos os métodos, tecnologias e ferramentas que auxiliaram na construção da ferramenta de DD DDidático.

\subsection{Scrum}

O Scrum é uma metodologia ágil de desenvolvimento que foi utilizada para o desenvolvimento da aplicação DDidático deste trabalho. Metodologias ágeis de desenvolvimento de software são iterativas, o que significa que são divididas em ciclos de desenvolvimento. No caso do Scrum, cada iteração é um Sprint [Blokehead and Barros 2017].

\subsection{GIT}

O GIT é um sistema de controle de versionamento, assim, ele funciona gravando mudanças em arquivos relacionando com o tempo das modificações, para que se possa voltar para versões específicas posteriormente [Chacon and Straub 2018]. Utilizar um sistema desse tipo, auxilia no desenvolvimento do código, pois se tem maior controle acerca das mudanças e funcionalidades incrementadas. Como repositório remoto, nesse trabalho, estaremos utilizando o GitLab, ferramenta de gerenciamento de repositório de software com gerenciamento de tarefas.

\subsection{Tecnologias Front-End}

Front-end é a parte da programação web que diz respeito a toda a apresentação gráfica do projeto. Como telas, botões, cores ou fontes. Dentre as tecnologias usadas no projeto estão: HTML e CSS, que servem para construção das páginas web e estilos; Javascript e JQuery, para construção de elementos dinâmicos na tela e animações; Ajax, para requisição ao banco de dados em situações que não seria possível atualizar a página; 
Bootstrap, que é um framework front-end que provê uma série de componentes e estilos, já prontos, para auxiliar o desenvolvedor a criar páginas de forma mais rápida.

\subsection{Tecnologias Back-End}

Enquanto o front-end lida com a parte de apresentação do aplicativo o back-end é o responsável por tratar dados, recuperação e armazenamento, além de processá-los. É no back-end que se encontram as lógicas de negócio, definições de papéis, e realização de ações no banco de dados. Para o desenvolvimento desse projeto foi escolhido o framework para desenvolvimento de aplicações Django Framework que utiliza a linguagem python para realizar suas tarefas.

\section{A ferramenta Web DDidático}

Após o preenchimento de um modelo de DD na DEaD - UERN, o professor envia um email para a equipe pedagógica iniciar a avaliação dos dados presentes no DD que o professor informou. Caso todos os dados inseridos pelo professor estejam coerentes com o que a disciplina propõe o avaliador passa o DD, também por email, para que a equipe de suporte possa inserir todas as suas informações de aulas e materiais didáticos na plataforma Moodle, o AVA utilizado pela DEaD.

Esse fluxo de trabalho tem alguns problemas, dentre eles, estão o documento para preencher pouco intuitivo, a dificuldade de acompanhar os estados do processo, pois, a utilização de emails para a troca de informação, dificulta a organização sistemática do processo de ofertas de disciplinas, além do recorrente problema de comunicação e mau entendidos.

A aplicação foi pensada para lidar com três tipos de intenção de uso do sistema, ou seja, existem 3 papéis dentro da aplicação: professor, avaliador e suporte.

Cabe ao usuário do tipo professor criar e editar DD's que ele tem na ferramenta, preenchendo os formulários criados para esse propósito. Nem sempre o professor preenche todos os dados da forma mais correta possível, por isso, foi pensado no papel do avaliador, que analisa os DD's e pode criar notas de correção, apontando para o professor onde aquele DD pode ser melhorado.

Já, por sua vez, o usuário do tipo suporte, apenas vê os DD's que estão prontos para serem inseridos na plataforma AVA e sinalizam que os dados foram inseridos. Além disso, o usuário do tipo suporte pode povoar o banco de dados no que diz respeito às disciplinas e informações sobre elas.

Para que pudessem ser analisados, de forma sistemática, os estágios de desenvolvimento que se encontram cada $\mathrm{DD}$, foi criado um sistema de estados que cada um significa um passo do processo.

De acordo com o que explica a Figura 1, assim que um desenho é criado no sistema ele recebe o estado de "pendente", pois ele está à espera da avaliação de um usuário do tipo avaliador analisar o desenho. O usuário avaliador, então, verifica os dados do desenho e, caso exista algum problema, o marca como "corrigir" para que o professor responsável por aquele desenho saiba que existe alguma alteração que precisa ser feita. Se o desenho está com o estado "corrigir" e o professor realizar alguma alteração de dados dentro dele seu estado volta para "pendente" e fica esperando uma nova avaliação. 


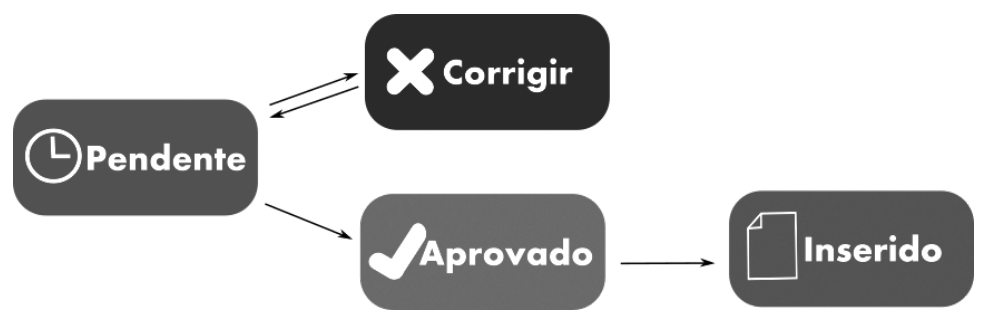

Figure 1. Estados de um DD

Quando o usuário avaliador verifica que todos os pontos dentro do DD estão corretos, marca seu estado para "aprovado", indicando para a equipe de suporte que aquele desenho já está pronto para ser adicionado no AVA. Assim que os usuários do tipo suporte cadastram o DD no Ambiente Virtual de Aprendizagem marcam seu estado para "inserido", finalizando o processo

Como já foi dito, cada núcleo ou diretoria $\mathrm{EaD}$ tem sua própria metodologia. $\mathrm{Na}$ Diretoria de Educação a Distância da UERN o DD segue a modelagem exemplificada na Figura 2, a seguir:

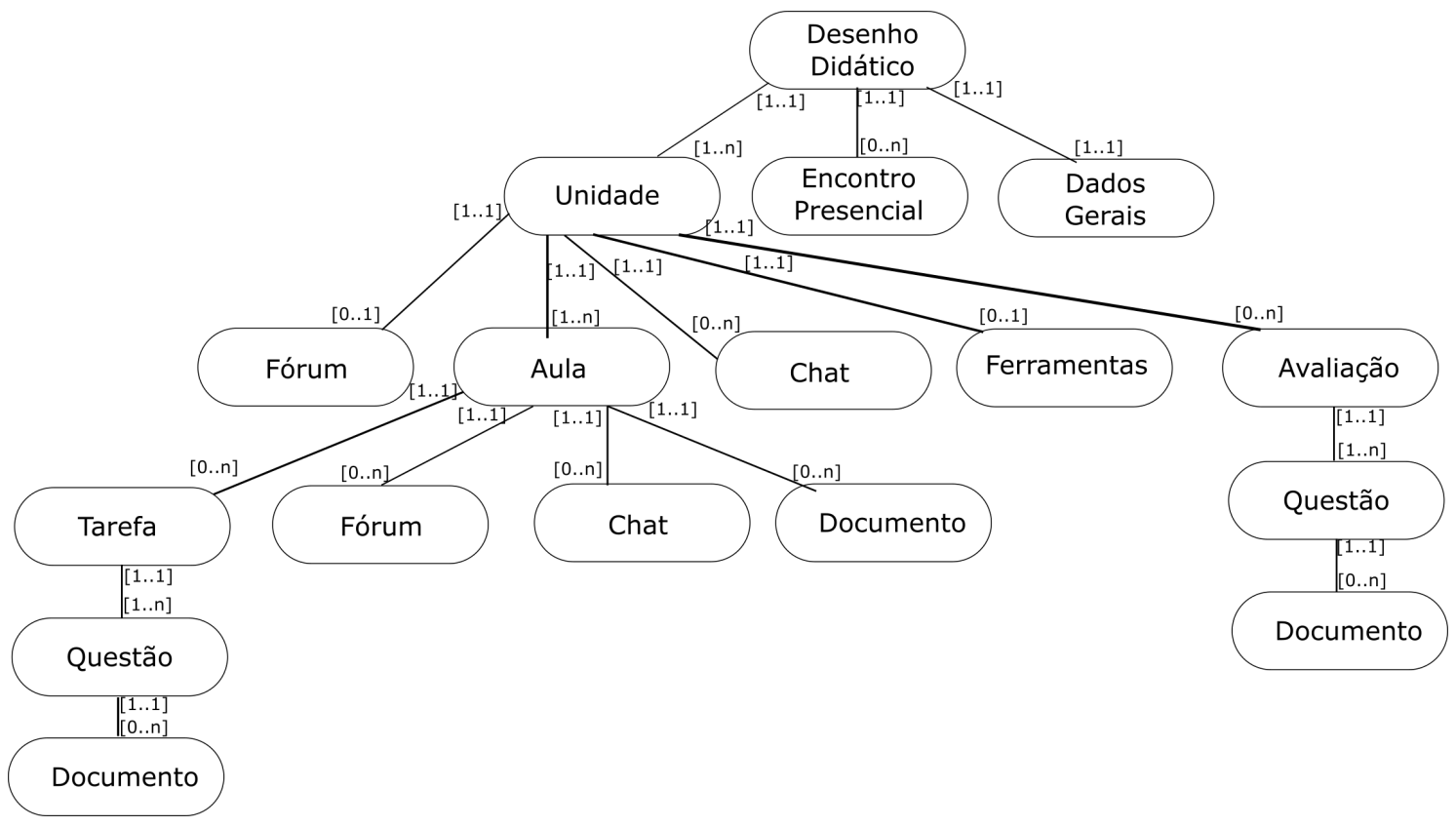

Figure 2. Modelagem de DD

Seguindo a modelagem da Figura 2, um DD possui uma ou mais unidades, nenhum ou mais encontros presenciais e, por fim, os seus dados gerais como nome da disciplina, semestre, curso, entre outros.

Cada unidade pode ter um fórum - sala de conversa com foco assíncrono -, várias aulas, nenhum ou vários chats - sala de conversa com foco síncrono -, nenhuma ou várias ferramentas (wiki), e nenhuma ou várias avaliações. Uma avaliação tem a intenção de avaliar quantitativamente um aluno, assim, pode ter uma ou várias questões e por questão podem ser inseridos nenhum ou vários documentos. Em cada aula de uma unidade, podem ser incluídos nenhuma ou várias tarefas, nenhum ou vários fóruns, nenhum ou vários chats 
e nenhum ou vários documentos de aula. Uma tarefa tem a função de fixar o conteúdo estudado naquela aula, dessa forma, podem ser incluídas uma ou mais questões e nenhum ou vários documentos por questão.

\subsection{Funcionalidades}

A aplicação se inicia na tela de login, na qual usuários previamente cadastrados inserem suas informações de usuário e senha para ter acesso aos recursos da aplicação. Após inserir seus dados corretamente no formulário, o usuário será redirecionado a uma visão da aplicação de acordo com o papel da sua conta, professor, avaliador ou suporte.

\subsubsection{Visão de Professor}

Como já foi dito, um usuário do tipo professor dentro da aplicação é o responsável pela criação e edição de seus respectivos desenhos. Na Figura 3 estão descritos, de modo geral, as funcionalidades do sistema feitas para professores

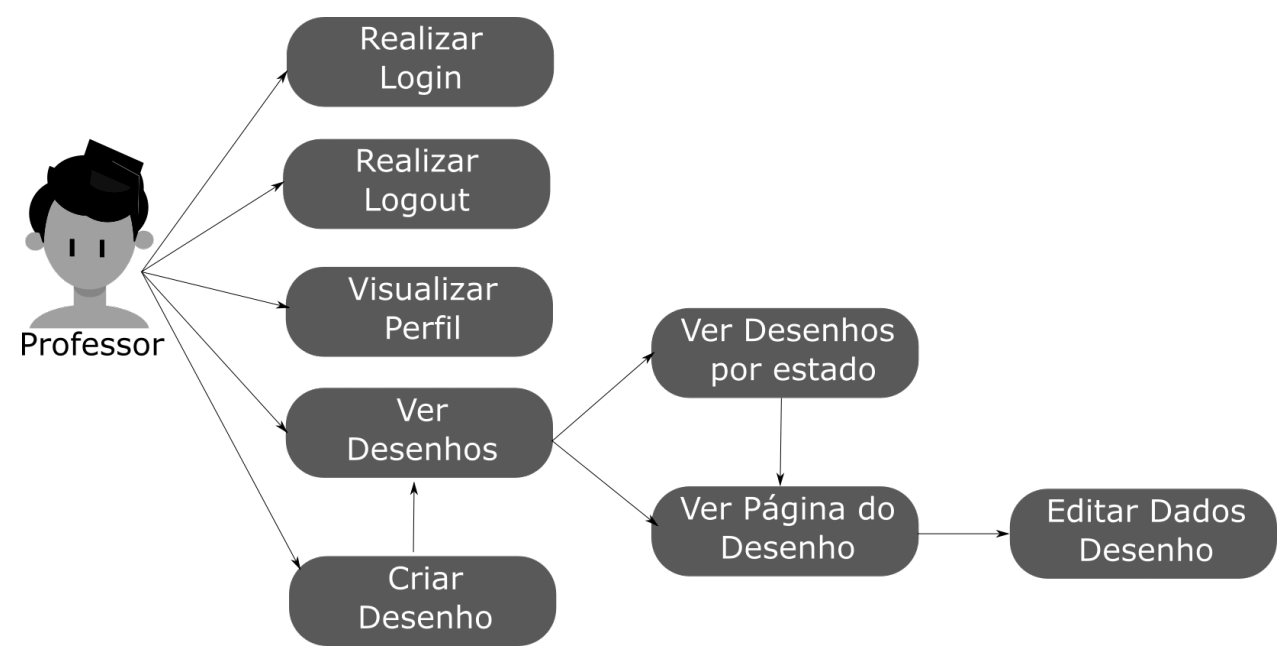

Figure 3. Funcionalidades de Professor

Além das funções de login e logout para ter acesso e sair da aplicação, um professor pode: Visualizar seu perfil. de forma a ver informações como nome de usuário, nome do professor, email e seu papel na aplicação; ver desenhos, para ter uma listagem de todos os desenhos que criou no sistema; filtrar os desenhos por estado; ver a página de um desenho específico; e realizar alterações nos dados de um desenho.

Assim que entra na aplicação, o professor tem acesso ao seu dashboard, ou tela de início, como é exibido na Figura 4. Nessa tela estão exibidos atalhos para algumas funcionalidades como criar um novo desenho, ver sua lista de desenhos, ver seus desenhos por corrigir.

Além disso, exibe uma lista de atividades recentes que podem ser de seu interesse. Em cada item de atividade recente é exibido quando aquela atividade foi executada, qual usuário realizou aquela ação, o que foi modificado e qual desenho foi o alvo da atividade, e clicando no alvo da atividade, o usuário é redirecionado para ele. 


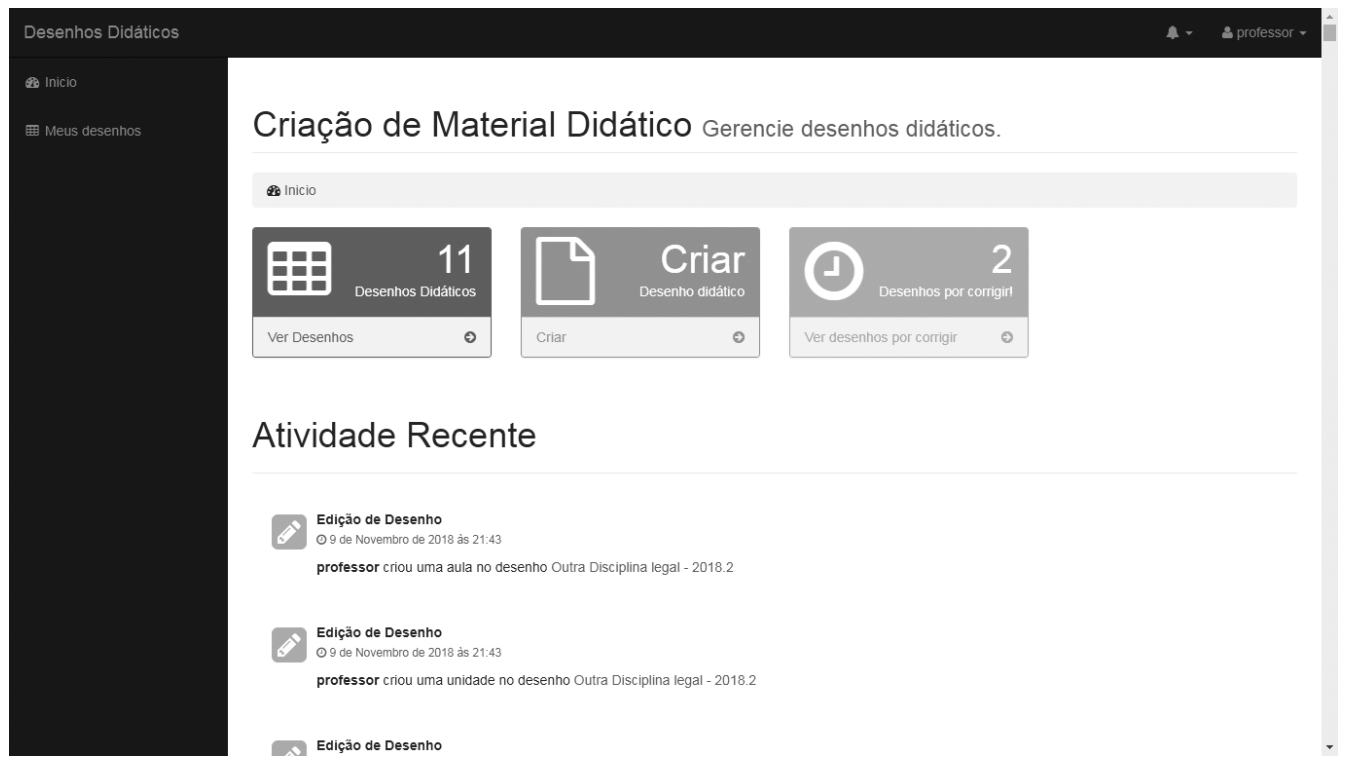

Figure 4. Tela de Dashboard do Professor

Na tela de "meus desenhos" do professor visualizada na Figura 5, o usuário com esse tipo vê todos os desenhos que criou no sistema. Por padrão, ele vê uma lista de desenhos em todos os estados, no entanto, existe um menu detalhado que o professor pode, se desejar, filtrar os seus desenhos por um tipo específico. Um desenho listado nessa página possui o nome da disciplina, o semestre que se refere, seu estado e um botão que direciona o usuário para a página de detalhamento daquele desenho. Nessa página, assim como no Dashboard, o professor pode criar um novo desenho, pois existe um botão para isso. Ao interagir com esse botão, é aberta uma janela de confirmação para ter certeza que o professor tem a intenção de criar um novo desenho, diminuindo as chances de enganos na aplicação.

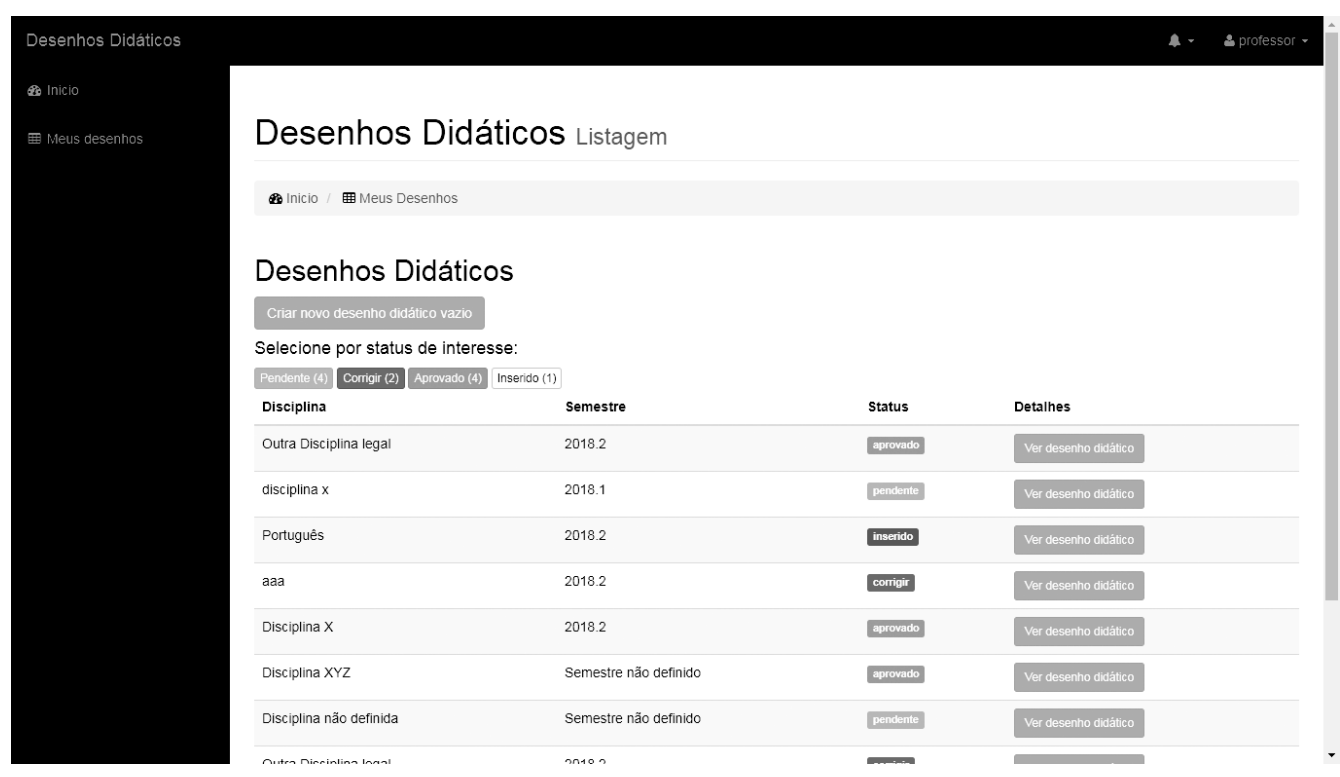

Figure 5. Tela de "meus desenhos" do Professor 
Quando um professor vai na página de um DD para visualizar seus detalhes verá que estarão nela as informações de estado do desenho (pendente, aprovado, corrigir, inserido), o nome do professor que criou o desenho, uma opção para deletar aquele DD específico e abas contendo mais detalhes do desenho. É também nessa tela que estão as opções de edição.

\subsubsection{Visão de Avaliador}

Um avaliador, confere se todos os dados de um DD, que se encontra pendente para receber avaliação, estão corretos e preenchidos adequadamente. A Figura 6 detalha as funcionalidades para esse usuário de forma geral.

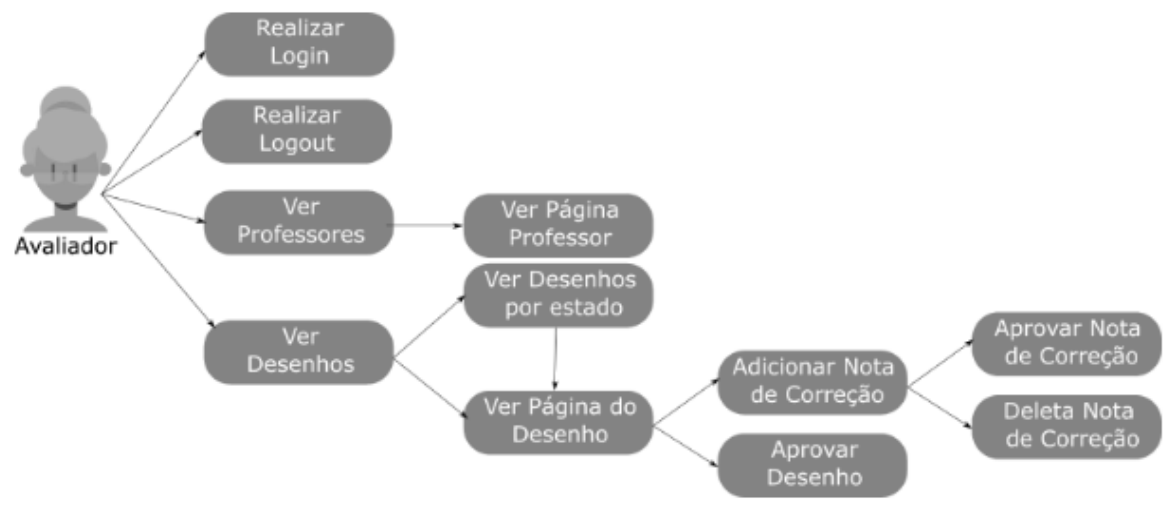

Figure 6. Funcionalidades de Avaliador

As funções de um avaliador são: login e logout para ter acesso e sair da aplicação; Ver lista de professores cadastrados e seus respectivos perfis com dados, seus DD's e lista de atividades no sistema; Listagem de DD's criados no sistema, além de ver a página de DD's específicos; Criar notas de correção em elementos de um DD para apontar ao professor onde deve corrigir o DD, aprovar ou deletar essa nota; Aprovar desenho didático.

Assim que entra na aplicação, o avaliador tem acesso a tela de início. Nela estão atalhos para funcionalidades principais como ver lista de professores cadastrados, ver DD's por pendentes para avaliar e por corrigir. Também exibe uma lista de atividades recentes que ocorreram na plataforma (criações, edições, etc).

\subsubsection{Visão de Suporte}

O usuário suporte apenas visualiza os DD's, caso sejam aprovados, e marcam como inseridos, assim que cadastram o desenho no AVA e tem a função de cadastrar cursos, ementas de cursos e disciplinas nessas ementas, com suas informações, de forma a "alimentar" o sistema para a criação de desenhos didáticos para os usuários professores. O suporte também é capaz de ver professores e seus perfis assim como um avaliador.

Além das funções de login e logout para ter acesso e sair da aplicação, o suporte pode:

- Ver lista de professores cadastrados; 
- Visualizar perfil de professor, de forma a ver informações como nome de usuário, nome do professor, email, atividades recentes, última atividade, e sua lista de desenhos didáticos (caso estejam com estado de aprovado ou inserido).

- Ver desenhos didáticos, para ter uma listagem de todos os desenhos criados no sistema ( aprovado ou inserido);

- Filtrar os desenhos por estado ( aprovado ou inserido);

- Ver a página de um desenho específico;

- Mudar estado de desenho didático para inserido, marcando como inserido no AVA;

- Criar e visualizar cursos que estão sendo ofertados;

A Figura 7, mostra de forma esquematizada suas funções dentro do sistema DDidático.

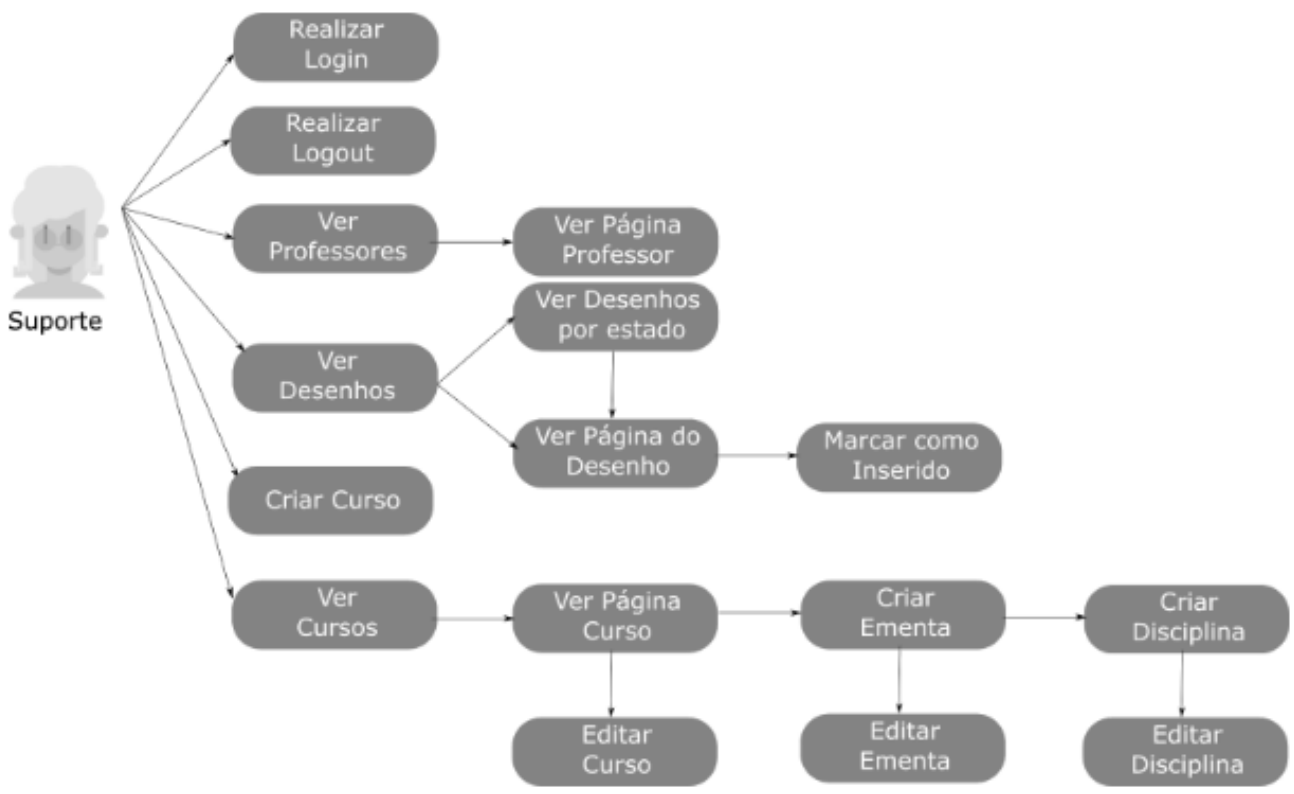

Figure 7. Funcionalidades de Suporte

\section{Considerações finais}

O Sistema para criação de desenho didático DDidático conseguiu ser implantado na DEaD da UERN com sucesso, de forma que passou a auxiliar nos processos de planejamento de disciplinas, e organização sistemática dos desenhos. Como foi feito de forma generalista, o sistema pode auxiliar durante muitos semestres que virão, pois novos cursos e disciplinas podem ser cadastrados.

Uma melhoria futura para o DDidático, seria a integração com o AVA, de forma a exportar automaticamente uma disciplina no Ambiente Virtual sem que seja preciso o usuário suporte fazer o cadastro manual.

O presente trabalho foi realizado com apoio da Coordenação de Aperfeiçoamento de Pessoal de Nível Superior - Brasil (CAPES). 


\section{References}

Blokehead, T. and Barros, R. (2017). Scrum - Guia de Práticas Ágeis Essenciais com Scrum! Babelcube Incorporated.

Brasil (2007). Referenciais de qualidade para educação a distância do mec. Ministério da Educação/Secretaria de Educação a Distância.

Brasil (2014). Lei $\mathrm{n}^{0}$ 13.005. aprova o plano nacional de educação - pne e dá outras providências. In Plano Nacional de Educação. Diário Oficial da União.

Chacon, S. and Straub, B. (2018). Pro Git: Everything you need to know about GIT. Apress, 1 th edition.

Neves, M., Centeno, C., Fruet, F., Otte, J., and Orth, M. (2012). Design educacional construtivista: $\mathrm{O}$ papel do design como planejamento na educação à distância. Simpósio Internacional de Educação à Distância.

Santiago, L. (2014). MADE: sistema de gestão e planejamento da matriz de design educacional de disciplinas a distância. Master's thesis, Universidade Estadual do Ceará.

Santos, E. and Silva, M. (2009). O desenho didático interativo na educação online. pages 267-287. Revista Ibero Americana de Educação. 